\title{
Características fermentativas e composição química de silagens de capim- elefante contendo subproduto desidratado do maracujá ${ }^{1}$
}

\section{Magno José Duarte Cândido ${ }^{2}$, José Neuman Miranda Neiva ${ }^{3}$, Norberto Mario Rodriguez ${ }^{4}$, Ana Cristina Holanda Ferreira ${ }^{5}$}

\author{
1 Pesquisa financiada pelo CNPq, pela CAPES e pela FUNCAP \\ 2 Departamento de Zootecnia, Universidade Federal do Ceará, Av. Mister Hull, 2977, Campus Universitário do Picí, Fortaleza - CE, 60970-355, \\ TEL: (85)3288-9703, FAX: (85)3288-9701. \\ ${ }^{3}$ Escola de Medicina Veterinária e Zootecnia, Universidade Federal de Tocantins - UFT, pesquisador do CNPq \\ ${ }^{4}$ Departamento de Zootecnia, Universidade Federal de Minas Gerais - UFMG. Pesquisador do CNPq. \\ 5 Escola de Medicina Veterinária e Zootecnia da Universidade Federal do Tocantins - UFT.
}

RESUMO - Avaliaram-se as características fermentativas e a composição químico-bromatológica de silagens de capimelefante contendo níveis crescentes de subproduto desidratado do maracujá (SDM). Foram testados cinco níveis de SDM $(0,0$; 3,$5 ; 7,0 ; 10,5$ e 14,0\%) em relação à matéria natural do capim, em um delineamento inteiramente casualizado, com quatro repetições. A gramínea foi cortada aos 60 dias de idade, triturada e ensilada, obtendo-se densidade de $600 \mathrm{~kg} / \mathrm{m}^{3}$. Após 28 dias, os silos foram abertos e amostras foram coletadas para análises laboratoriais. Os níveis crescentes de SDM tiveram efeito linear crescente sobre o teor de MS das silagens e efeito linear decrescente sobre o teor de ácido propiônico. Houve efeito quadrático com ponto de máximo para o teor de ácido lático. Os teores de ácido butírico foram desprezíveis. Os valores de pH e os teores de $\mathrm{N}$-amoniacal, de ácido acético e de FDA não foram afetados. Verificou-se efeito linear dos níveis crescentes de SDM sobre os teores de PB e de EE das silagens. Os teores de FDN e hemicelulose das silagens foram afetados pelos níveis crescentes de SDM, com resposta linear decrescente. A adição de SDM na ensilagem do capim-elefante favoreceu o processo fermentativo e melhorou a composição químico-bromatológica das silagens, portanto, esse subproduto pode ser utilizado em quantidades de até $14 \%$ em relação à matéria natural da gramínea.

Palavras-chave: fibra em detergente neutro, fibra em detergente ácido, nitrogênio amoniacal, pH, proteína bruta

\section{Fermentative patterns and chemical composition of elephantgrass silages with dehydrated passionfruit byproduct}

\begin{abstract}
The fermentative characteristics and the chemical composition of elephant grass silages with increasing levels of dehydrated passionfruit by-product (DPB) were evaluated. Five DPB addition levels $(0.0 ; 3.5 ; 7.0 ; 10.5 ;$ and $14.0 \%$; in a grass fresh matter basis), in a complete randomized design with four replicates were studied. The grass was cut at 60 days of age, chopped, and ensiled, reaching a packing density of $600 \mathrm{~kg} / \mathrm{m}^{3}$. After 28 days of ensiling, the silos were opened and samples were collected for laboratory analysis. Addition of DPB promoted a linear increasing effect on the silages dry matter and a linear decreasing effect on the propionic acid levels. A quadratic effect with maximum point of the DPB increasing levels on the silages lactic acid levels was verified. The butyric acid levels were negligible. The $\mathrm{pH}$ values, $\mathrm{N}$-ammonia, acetic acid, and the acid detergent fibre levels were not affected. A linear effect of the DPB increasing levels was verified on the crude protein and the ether extract concentrations. A linear decreasing effect of the DPB increasing levels on the silages NDF and hemicellulose concentration was observed. The DPB addition up to the level of 14\% (on a grass fresh matter basis) at the elephantgrass ensiling promoted a good fermentative pattern and a better silage chemical composition.
\end{abstract}

Key Words: acid detergent fiber, crude protein, $\mathrm{N}$ ammonia, neutral detergent fiber, $\mathrm{pH}$

\section{Introdução}

A irregularidade de distribuição das chuvas ocorridas na Região Nordeste afeta a produtividade de seus rebanhos, por reduzir significativamente a oferta de alimento volumoso aos animais no período da seca.
A utilização de silagem como alimento volumoso é uma prática crescente por garantir a manutenção dos rebanhos durante este período. De acordo com Nussio et al. (2002), em alguns lugares do mundo, a produção de silagens contribui com 10 a $25 \%$ dos alimentos destinados a animais ruminantes e representa $2 \%$ do 
suprimento de alimentos suplementares, como média global.

Entre as gramíneas tropicais utilizadas na produção de silagens, o capim-elefante (Pennisetum purpureum Schum.) tem grande aceitação na Região Nordeste, em razão de seu elevado potencial de produção de MS e do seu bom valor nutritivo. Entretanto, o elevado teor de umidade na idade de maior valor nutritivo e o alto poder tampão são fatores que inibem o adequado processo fermentativo, dificultando a obtenção de silagens de boa qualidade (McDonald et al., 1991).

Para minimizar esses problemas, pode-se promover a adição de subprodutos de frutos tropicais após sua desidratação. Esses subprodutos, gerados em grande quantidade na Região Nordeste, são poluidores do meio ambiente quando não têm destino adequado.

Além de contribuírem para a melhoria do padrão fermentativo das silagens de capim-elefante, muitos desses subprodutos, por apresentarem elevado valor nutritivo, como o subproduto do maracujá (Passiflora edulis Sims f. flavicarpa) (Lousada Jr. et al., 2005; Lousada Jr. et al., 2006), quando adicionados em níveis adequados, podem contribuir para o aumento do valor nutritivo das silagens produzidas.

Esta pesquisa foi conduzida com o objetivo de avaliar os efeitos da adição de níveis do subproduto desidratato do maracujá sobre as características fermentativas e a composição químico-bromatológica de silagens de capimelefante.

\section{Material e Métodos}

O experimento foi realizado no Núcleo de Pesquisa em Forragicultura do Departamento de Zootecnia/CCA/UFC, em Fortaleza - CE, no período de 11 de fevereiro a 5 de março de 2003. O município de Fortaleza situa-se na Zona Litorânea, a $15,49 \mathrm{~m}$ de altitude, $3^{\circ} 43^{\prime} 02^{\prime \prime}$ de latitude Sul e $38^{\circ} 32^{\prime} 35^{\prime \prime}$ de longitude Oeste.

Foram avaliados cinco níveis de adição do subproduto desidratado de maracujá $(0,0 ; 3,5 ; 7,0 ; 10,5$ e $14,0 \%$ em relação à matéria natural do capim-elefante) em um delineamento inteiramente casualizado, com quatro repetições.

Na confecção das silagens experimentais, utilizou-se capim-elefante (Pennisetum purpureum, Schum) proveniente de uma capineira já estabelecida na Fazenda Experimental Vale do Curu, em Pentecoste-CE, pertencente à UFC. Após o corte de uniformização, a área recebeu adubação de cobertura, com $50 \mathrm{~kg}$ de N/ha na forma de uréia e $40 \mathrm{~kg}$ de $\mathrm{K}_{2} \mathrm{O}$ /ha na forma de cloreto de potássio. A gramínea foi cortada manualmente aos 60 dias de idade e, posteriormente, foi triturada em máquina picadora de forragem.
O resíduo de maracujá utilizado no experimento foi originado da fabricação de sucos pela empresa MAISA em Mossoró - RN, onde foi submetido à desidratação ao sol até apresentar 13 a $16 \%$ de umidade. Durante o processo de desidratação, o material foi revolvido três vezes ao dia e, à noite, foi amontoado e coberto com lona para evitar acúmulo de umidade.

Por ocasião da ensilagem, o capim-elefante apresentava 16,7\% de MS, 6,5\% de PB, 79,7\% de FDN, 46,9\% de FDA, 32,8\% de hemicelulose e $3,4 \%$ de EE. O subproduto desidratado de maracujá apresentava 83,3\% de MS, $12 \%$ de PB, 56,4\% de FDN, 49,0\% de FDA, 9,5\% de hemicelulose e 1,0\% de EE.

Como silos experimentais foram utilizados tambores de plástico com capacidade para 200 L. Após pesagem e homogeneização do capim-elefante com resíduo de maracujá, o material foi compactado no interior do silo, por meio de pisoteamento por homens. Completado o enchimento, os silos foram fechados com lonas plásticas presas com ligas de borracha. Em cada silo, foram colocados $125 \mathrm{~kg}$ de forragem, de forma que se atingisse densidade de $600 \mathrm{~kg} / \mathrm{m}^{3}$.

Após 28 dias, os silos foram abertos. Amostras das silagens foram coletadas e armazenadas em congelador a $-10^{\circ} \mathrm{C}$ até a época das análises laboratoriais. Uma amostra foi retirada de cada tambor e congelada para determinação de $\mathrm{N}$-amoniacal e $\mathrm{pH}$. O pH foi determinado conforme Silva \& Queiroz (2002) e o N-amoniacal, segundo metodologia adaptada por Cândido (2000). Os ácidos orgânicos (lático, acético, butírico e propiônico) foram determinados por cromatografia de fase líquida de alta eficiência (HPLC), segundo metodologia descrita por Mathew et al. (1997), filtrando-se aproximadamente $2 \mathrm{~mL}$ do sobrenadante de cada amostra de suco da silagem em membrana de acetato de celulose com porosidade $0,45 \mu \mathrm{m}$.

Outra amostra foi mantida em estufa de ventilação forçada a $65^{\circ} \mathrm{C}$ por 72 horas e, em seguida, foi moída para determinação dos teores de MS, PB, FDN, FDA e EE, segundo metodologia descrita por Silva \& Queiroz (2002). O teor de hemicelulose foi calculado como a diferença entre os teores de FDN e FDA.

Para análise estatística, realizou-se um estudo para verificar se as pressuposições de distribuição normal, de aditividade e de homocedasticidade dos dados foram atendidas. Apenas o valor de $\mathrm{pH}$ sofreu transformação inversa para se prosseguir com essas análises.

Realizaram-se análises de variância e de regressão. A adoção ou não de um modelo baseou-se na significância dos coeficientes linear, quadrático e cúbico utilizando-se o teste t de Student a $5 \%$ de probabilidade. Como ferramenta de auxílio às análises estatísticas, utilizou-se o procedimento GLM do programa estatístico SAS (SAS, 1999). 


\section{Resultados e Discussão}

De acordo com a análise de regressão, os níveis crescentes de SDM tiveram efeito linear $(\mathrm{P}<0,1)$ sobre o teor de matéria seca (MS) das silagens (Figura 1), que variou de $15,1 \%(0 \%$ de SDM) a $24,6 \%$ (14\% de SDM). Para cada $1 \%$ de adição de SDM, verificou-se elevação de 0,68 ponto percentual no teor de MS das silagens (Figura 1) como consequiência do reduzido teor umidade após a desidratação do subproduto.

Rodrigues et al. (2005), ensilando capim-elefante com níveis crescentes de polpa cítrica peletizada, observaram elevação $(\mathrm{P}<0,1)$ de 0,5 ponto percentual no teor de MS a cada $1 \%$ de adição do subproduto, mesmo resultado observado por Gonçalves et al. (2004), na ensilagem de capimelefante com níveis crescentes de subprodutos de acerola e goiaba. Esses autores observaram elevação $(\mathrm{P}<0,1)$ de 11,35 e de 10,80 pontos percentuais, respectivamente, no teor de MS das silagens quando os níveis de subproduto aumentaram de 0 para $20 \%$. De modo geral, essas respostas deveram-se ao elevado teor de MS dos subprodutos $(86,5$; 87,11 e $88,8 \%$, respectivamente).

Embora estes dados comprovem que a adição de SDM durante a ensilagem de capim-elefante eleve o teor de MS das silagens produzidas, é importante destacar que o teor máximo obtido $(24,6 \% \mathrm{MS})$ no nível de $14 \%$ de adição foi inferior ao mínimo (30 a 35\% de MS) característico de silagens de boa qualidade (Mcdonald et al., 1991). Esse resultado pode ser explicado pelo alto teor de umidade do capim-elefante, que apresentou apenas $15,1 \%$ de MS no momento do corte. Resalta-se que a adição de $14 \%$ de SDM propiciou elevação de 9,5 pontos percentuais no teor de MS das silagens.
Vale salientar que o teor de MS não determina, por si, a qualidade da silagem. Outras variáveis, como o teor de carboidratos solúveis da planta, podem favorecer a fermentação, resultando em silagem de boa qualidade (Cândido et al., 2002).

Os níveis de SDM tiveram efeito linear $(\mathrm{P}<0,1)$ sobre o teor de PB das silagens, que variou entre $6,1 \%$ ( $0 \%$ de SDM) e $8,8 \%$ ( $4 \%$ de SDM), com aumento de 0,19 pontos percentual para cada $1 \%$ de adição de SDM (Figura 2). A adição de 4,8\% de SDM permitiu que o teor mínimo de 7,0\% de PB fosse suficiente para o bom funcionamento ruminal. Esse efeito benéfico da adição do SDM sobre o teor de PB das silagens está relacionado ao maior teor desse nutriente no resíduo em relação ao capim-elefante.

Ferreira et al. (2004) ensilaram capim-elefante com níveis crescentes de bagaço de caju e observaram efeito benéfico do subproduto sobre o teor de PB das silagens até o nível de $36 \%$. Esse resultado deveu-se ao teor mais elevado desse nutriente no subproduto $(14,2 \%)$ em relação ao capim-elefante $(3,3 \%)$.

$\mathrm{O}$ teor de FDN das silagens foi influenciado $(\mathrm{P}<0,1)$ pelos níveis de SDM e apresentaram resposta linear decrescente (Figura 3). A cada 1\% de adição do SDM, o teor de FDN reduziu em 0,61 ponto percentual, com variação de 79,24 até 70,7\% nos níveis de 0 e de 14\% de SDM, respectivamente. Esse efeito dos níveis de SDM em reduzir o teor de FDN das silagens pode ser atribuído ao seu menor teor desse nutriente $(59,2 \%)$. Os dados obtidos neste trabalho corroboram os descritos por Pompeu et al. (2006), que obtiveram decréscimos nos teores de FDN em torno de 0,30 ponto percentual para cada $1 \%$ de adição de SDN em silagens de capim-elefante.

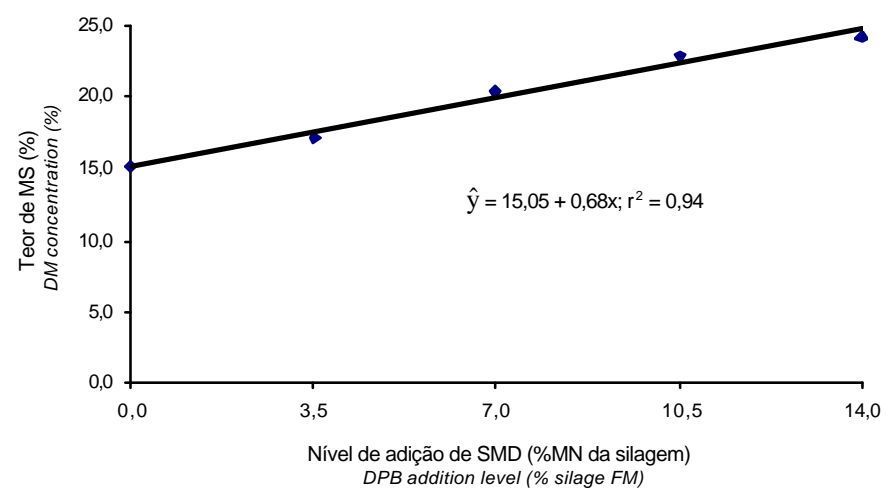

Figura 1 - Teor de MS de silagens de capim-elefante produzidas com subproduto desidratado de maracujá (SDM).

Figure 1 - Silage DM concentration as affected by the dehydrated passion fruit byproduct (DPB) addition level.

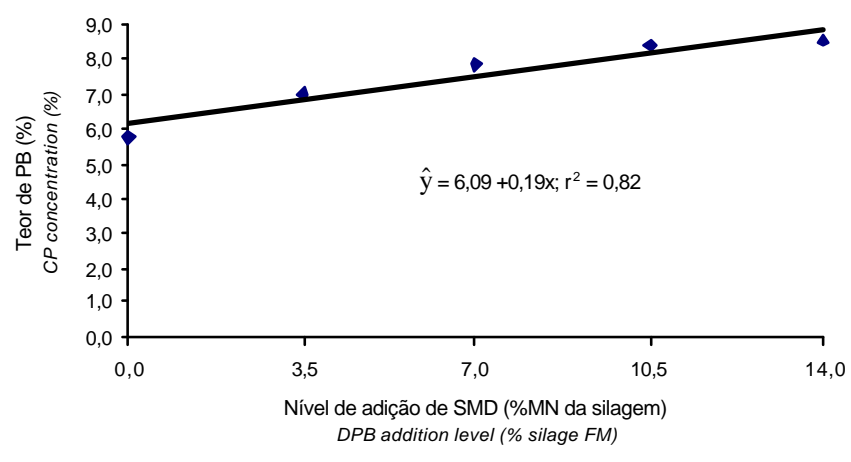

Figura 2 - Teor de PB de silagens de capim-elefante produzidas com subproduto desidratado de maracujá (SDM).

Figure 2 - Silage $C P$ concentration as affected by the dehydrated passion fruit byproduct (DPB) addition level. 
Ferreira et al. (2004) avaliaram o valor nutritivo de silagens de capim-elefante com níveis crescentes de bagaço de caju e observaram redução de 3,8 pontos percentuais no teor de FDN das silagens com a adição de $36 \%$ do subproduto, em razão do menor teor desse nutriente no bagaço de caju $(65,5 \%)$ em comparação ao capim-elefante $(76,7 \%)$.

Apesar da redução no teor de FDN, as silagens ainda apresentaram valor nutritivo limitado, pois, segundo Van Soest (1965), em níveis de FDN iguais ou superiores a 70\%, ocorre limitação no consumo do alimento pelo efeito físico de enchimento do rúmen.

Os teores de FDA das silagens não foram afetados ( $\mathrm{P}>0,1$ ) pelos níveis de SDM e variaram de 46,4 a 49,8\%, com média de $48,2 \pm 1,3 \%$, o que provavelmente está relacionado ao elevado teor desse nutriente no subproduto (49,0\%), próximo ao do capim-elefante, que aos 70 dias de idade apresenta em torno de $44 \%$ de FDA. Portanto, a inclusão desse subproduto nas silagens não reduz o teor de FDA das silagens. Esse elevado teor de FDA das silagens implica limitações ao consumo dessas silagens, pois esse nutriente constitui a parte mais indigestível da fibra presente nos volumosos.

O teor de hemicelulose das silagens apresentou resposta linear decrescente $(\mathrm{P}<0,1)$ aos níveis de SDM (Figura 3 ). A cada $1 \%$ de adição de SDM, verificou-se redução de 0,66 ponto percentual no teor de hemicelulose, que variou de 31,5 a 22,3\% nos níveis de 0 e de $14 \%$ de SDM, respectivamente. Essa redução no teor de hemicelulose deveu-se

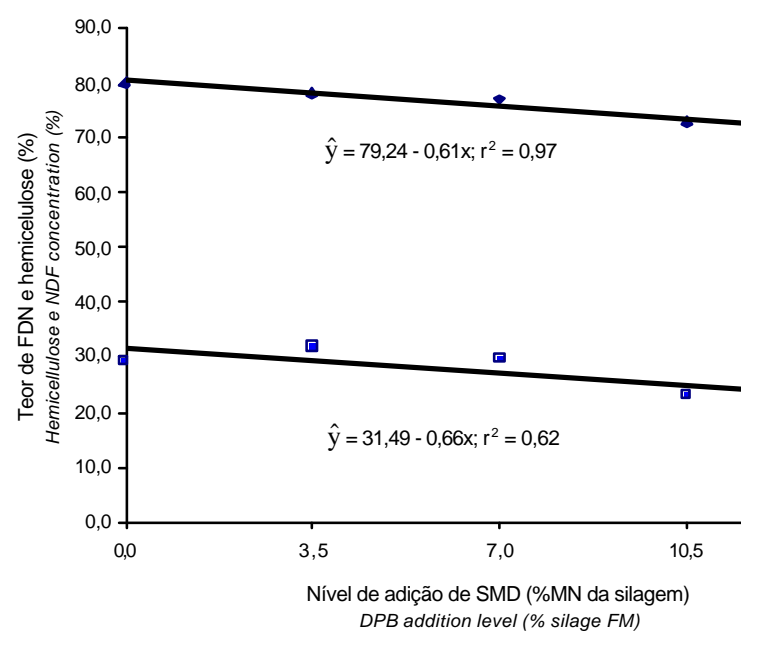

Figura 3 - Teores de FDN e hemicelulose de silagens de silagens de capim-elefante produzida com subproduto desidratado de maracujá (SDM).

Figure 3 - NDF (above) and hemicellulose (below) concentration as affected by the dehydrated passionfruit byproduct (DPB) addition levels. basicamente à redução no teor de FDN das silagens, uma vez que não houve efeito $(\mathrm{P}>0,1)$ dos níveis de SDM sobre o teor de FDA das silagens. Como a redução no teor de hemicelulose foi proporcional à redução no teor de FDN, não houve perda da hemicelulose por fermentação.

$\mathrm{O}$ pH não foi afetado $(\mathrm{P}>0,1)$ pelos níveis de SDM e variou de 3,8 a 4,1, com média de 3,9. Ressalta-se que o pH manteve-se abaixo do valor máximo permitido para a caracterização de silagens de boa qualidade, ou seja 4,2 (Mcdonald et al., 1991). Valores de $\mathrm{pH}$ superiores a 4,2 indicam má fermentação, sem predominância da atuação das bactérias lácticas, fundamentais para acidificação adequada do meio e alcance da estabilidade anaeróbia. Os valores de $\mathrm{pH}$ obtidos neste trabalho estão de acordo com os encontrados por Pompeu et al. (2006) em silagens de capim-elefante produzidas com 0 a $20 \%$ de subproduto desidratado de maracujá. Ferreira et al. (2004) e Gonçalves et al. (2004) também não observaram comprometimento das silagens de capim-elefante acrescidas de subprodutos de caju, acerola e goiaba.

$\mathrm{O}$ teor de $\mathrm{N}$-amoniacal das silagens não foi afetado ( $\mathrm{P}>0,1)$ pelos níveis de SDM e apresentou variação de 7,4 a 9,9, com média de 8,6. Esses valores foram inferiores ao máximo permitido (12\%) para a caracterização de silagens de boa qualidade (McDonald et al., 1991). Quanto maior o teor de $\mathrm{N}$-amoniacal, menor a qualidade da silagem, ou seja, ocorre degradação de compostos protéicos (proteína verdadeira, peptídios, aminoácidos, aminas e amidas) pelas

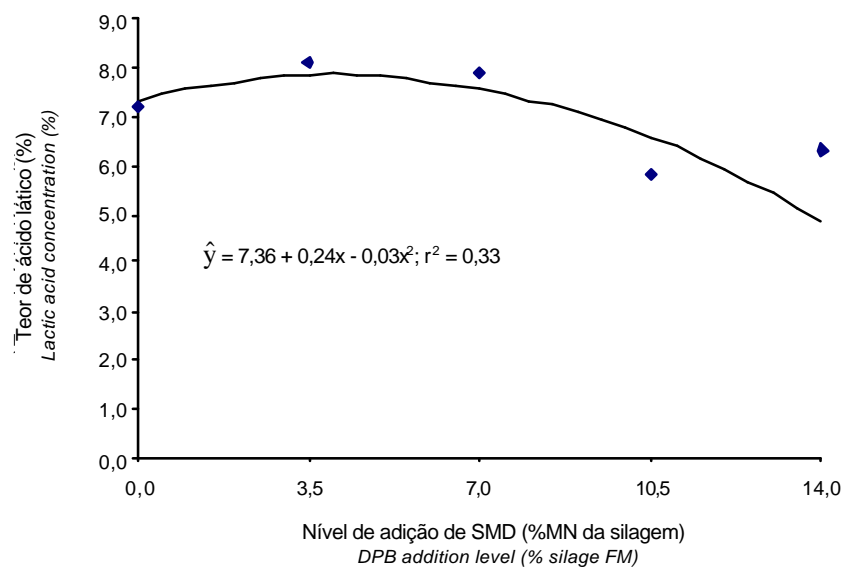

Figura 4 - Teor de ácido lático (AP) de silagens de capimelefante produzidas com subproduto desidratado de maracujá (SDM).

Figure 4 - Lactic acid (LA) concentration as affected by the dehydrated passionfruit byproduct (DPB) addition level. 
bactérias do gênero Clostridium até amônia, a qual é perdida por volatilização durante a abertura do silo.

As silagens de capim-elefante produzidas sem o subproduto ( $0 \%$ de SDM) deveriam ter apresentado $\mathrm{pH}$ e níveis de $\mathrm{N}$-amoniacal mais elevados em virtude dos baixos teores de MS (28 a 35\%). No entanto, possivelmente, a boa compactação propiciou adequada expulsão do excesso de oxigênio e favoreceu a fermentação no interior dos silos.

O teor de ácido lático foi afetado $(\mathrm{P}<0,1)$ pelos níveis de SDM. Na análise de regressão, observou-se efeito quadrático $(\mathrm{P}<0,1)$, com teor máximo estimado de $7,85 \%$ de ácido lático com a adição de $4,06 \%$ de SDM (Figura 4). Esse teor foi superior ao citado por Roth \& Heinrichs (2001). De qualquer modo, o elevado poder de dissociação de $\mathrm{H}^{+}$contido no ácido lático (Moisio \& Heikonen, 1994) permite que o elevado teor de ácido lático do SDM contribua para a redução no $\mathrm{pH}$ das silagens, principalmente no caso do capim-elefante, que, pelo seu elevado teor de água à ensilagem, apresenta elevado poder tampão.

O teor de ácido acético das silagens não foi influenciado (P>0,1) pelos níveis de SDM e variou de 1,03 a 1,78\%, com média de 1,33. Esses valores foram inferiores ao máximo permitido (2\%) para a caracterização de silagens de boa qualidade (Roth \& Heinrichs, 2001).

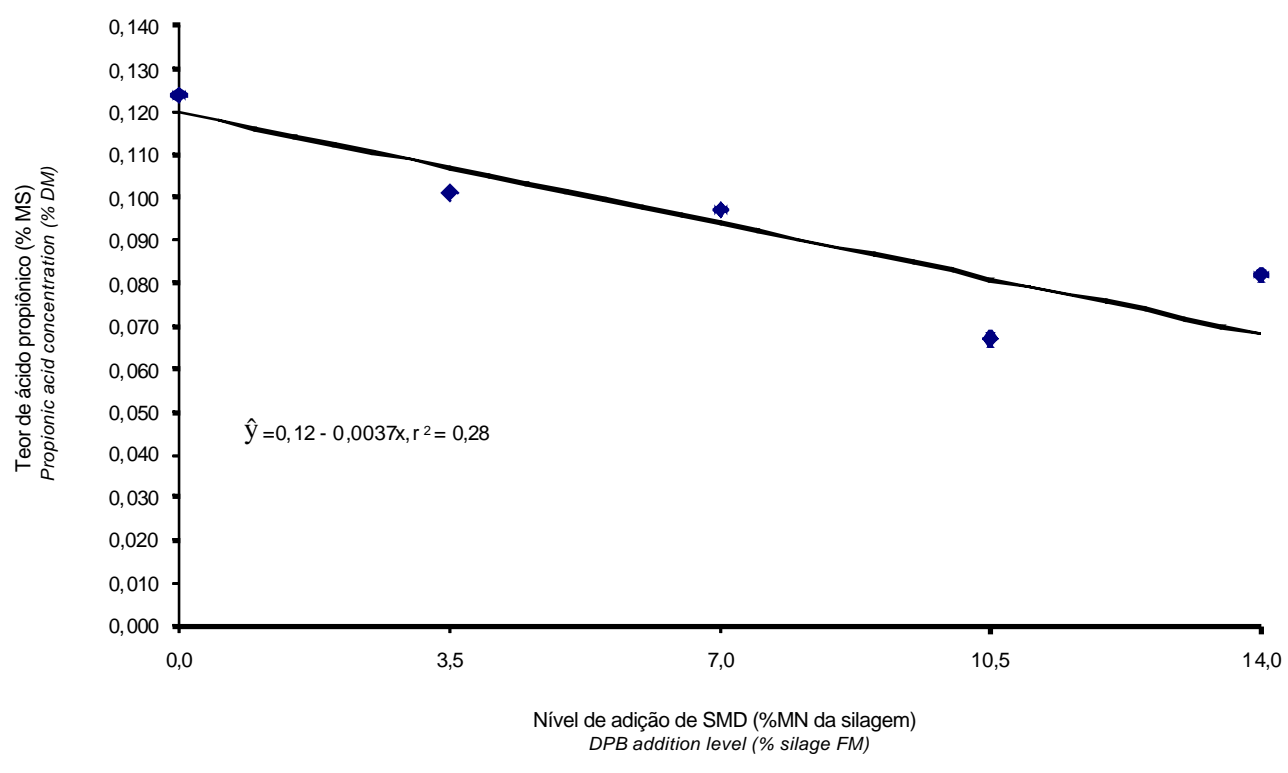

Figura 5 - Teor de ácido propiônico (AP) de silagens de capim-elefante produzidas com subproduto desidratado de maracujá (SDM). Figure 5 - Propionic acid (PA) concentration as affected by the dehydrated passionfruit byproduct (DPB) addition level.

Os níveis de SDM afetaram $(\mathrm{P}<0,1)$ o teor de ácido propiônico das silagens provocando efeito linear decrescente $(\mathrm{P}<0,1)$ sobre esta variável (Figura 5). Conforme a equação de regressão, a cada $1 \%$ de adição de SDM, houve redução de 0,0037 ponto percentual no teor de ácido propiônico das silagens. Foram estimados teores de 0,12 e de $0,07 \%$ para os níveis extremos de adição de SDM nesta pesquisa (0 e $14 \%$, respectivamente), portanto, mesmo no menor nível de adição do SDM, o teor de ácido propiônico já era desprezível.

O teor de ácido butírico variou de 0,0 a 0,2\% (dados não apresentados). Não foi realizada análise estatística, em razão da grande freqüência de valores iguais a zero, o que demonstra a adequação do processo fermentativo, uma vez que a presença deste ácido é característica de silagens com predominância da fermentação clostrídica, indesejável no processo conservativo.

Considerando o teor de MS, o pH, os teores de $\mathrm{N}$-amoniacal e dos ácidos lático, acético e propiônico, pode-se depreender que a adição do SDM à ensilagem de capim-elefante favoreceu o processo fermentativo, pois elevou o teor de MS da massa ensilada e propiciou a fermentação láctica, inibindo a fermentação clostrídica, com repercussões positivas na manutenção do $\mathrm{pH}$ adequado e de baixos teores de $\mathrm{N}$-amoniacal, provavelmente em razão da reduzida proteólise na massa ensilada. Portanto, considerando as características fermentativas, não há limitações para o uso do SDM em níveis de até 14,0\% (com base na matéria natural) na ensilagem de capim-elefante. 


\section{Conclusões}

A adição de subproduto desidratado de maracujá em níveis de até $14 \%$ da matéria natural do capim-elefante durante a ensilagem favorece o processo fermentativo e melhora a composição químico-bromatológica da silagem.

\section{Literatura Citada}

AQUINO, D.C.; NEIVA, J.N.M.; MORAES, S.A. et al. Avaliação do valor nutritivo da silagem de capim-elefante (Pennisetum purpureum, Schum) com diferentes níveis de subproduto do maracujá (Passiflora edulis). In: REUNIÃO ANUAL DA SOCIEDADE BRASILEIRA DE ZOOTECNIA, 40., 2003, Santa Maria, 2003. Anais... Santa Maria: Sociedade Brasileira de Zootecnia, 2003. (CD-ROM).

CÂNDIDO, M.J.D.; OBEID, J.A.; PEREIRA, O.G et al. Características fermentativas e potencial biológico de silagens de híbridos de sorgo cultivados com doses crescentes de adubação. Revista Ceres, v.49, p.151-167, 2002.

CÂNDIDO, M.J.D. Qualidade e valor nutritivo de silagens de híbridos de sorgo (Sorghum bicolor (L.) Moench) sob doses crescentes de recomendação de adubação. Viçosa, MG: Universidade Federal de Viçosa, 2000. 57p. Dissertação (Mestrado em Zootecnia) - Universidade Federal de Viçosa, 2000

FERREIRA, A.C.H.; NEIVA, J.N.M.; RODRIGUEZ, N.M. et al. Valor nutritivo das silagens de capim-elefante com diferentes níveis de subprodutos da indústria do suco de caju. Revista Brasileira de Zootecnia, v.33, n.6, p.1380-1385, 2004.

GONÇALVES, J.S.; NEIVA, J.N.M.; VIEIRA, N.F. et al. Valor nutritivo de silagens de capim-elefante (Pennisetum purpureum Schum.) com adição de diferentes níveis dos subprodutos do processamento de acerola (Malpighia glabra L.) e de goiaba (Psidium guajava L.). Revista Ciência Agronômica, v.35, n.1, p.131-137, 2004.

LOUSADA JR., J.E.; COSTA, J.M.C.; NEIVA, J.N.M. et al. Caracterização físico-química de subprodutos obtidos do processamento de frutas tropicais visando seu aproveitamento na alimentação animal. Revista Ciência Agronômica, v.37, n.1, p.70-76, 2006

LOUSADA JR., J.E.; NEIVA, J.N.M.; RODRIGUEZ, N.M. et al. Consumo e digestibilidade aparente de subprodutos do processamento de frutas em ovinos. Revista Brasileira de Zootecnia, v.34, n.2, p.591-601, 2005.
MATHEW, S.; SAGATHEVAN, S.; THOMAS, J. et al. An HPLC method for estimation of volatile fatty acids in ruminal fluid. Indian Journal of Animal Science, v.67, n.9, p.805-807, 1997.

McDONALD, P.; HENDERSON, A.R.; HERON, S.J.E. The biochemistry of silage . 2.ed. Marlow: Chalcombe, 1991. 340p. MOISIO, T.; HEIKONEN, M. Lactic acid fermentation in silage preserved with formic acid. Animal Feed Science and Technology, v.47, n.1-2, p.107-124, 1994.

NUSSIO, L.G.; PAZIANI, S.F.; NUSSIO, C.M.B. Ensilagem de capins tropicais. In: REUNIÃO ANUAL DA SOCIEDADE BRASILEIRA DE ZOOTECNIA, 39., 2002, Recife. Anais... Recife: Sociedade Brasileira de Zootecnia, 2002. p.60-90.

POMPEU, R.C.F.F.; NEIVA, J.N.M.; CÂNDIDO, M.J.D. et al. Valor nutritivo de silagens de capim-elefante (Pennisetum purpureum Schum.) com adição de subprodutos do processamento de frutas tropicais. Revista Ciência Agronômica, v.37, n.1, p.77-83, 2006.

REIS, J.; PAIVA, P.C.A.; von TIESENHAUSEN, I.M.E.V. et al. Composição química, consumo voluntário e digestibilidade de silagens de resíduos de fruto de maracujá (Passiflora edulis Sims. f. flavicarpa) e de capim-elefante (Pennisetum purpureum Schum.) cv. Cameroon e suas combinações. Ciência e Agrotecnologia, v.24, n.1, p.213-224, 2000.

RODRIGUES, P.H.M.; BORGATTI, L.M.O.; GOMES, R.W. et al. Efeito da adição de níveis crescentes de polpa cítrica sobre a qualidade fermentativa e o valor nutritivo da silagem de capimelefante. Revista Brasileira de Zootecnia, v.34, n.4, p.1138-1145, 2005.

ROTH, G.W.; HEINRICHS, A.J. [2001].Corn silage production and management. Disponível em: <http://cropsoil.psu.edu/ extension/facts/agfact18.pdf.> Acesso em: 22/4/2006.

STATISTICAL ANALYSIS SYSTEM - SAS. SAS system for windows. Version 8.0. Cary: 1999. (CD-ROM).

SILVA, D.J.; QUEIROZ, A.C. Análise de alimentos: métodos químicos e biológicos. 3.ed. Viçosa, MG: Editora UFV, 2002. 235 p.

Van SOEST, P.J. Voluntary intake in relation to chemical composition and digestibility. Journal of Animal Science, v.24, n.3, p.834$843,1965$. 